\title{
The association of Angelman's syndrome with deletions within 15q11-13
}

\author{
M PEMBREY*, S J FENNELL $\dagger$, J VAN DEN BERGHE*, M FITCHETT $\ddagger$, \\ D SUMMERS§, L BUTLER \&, C CLARKE†, M GRIFFITHS \\ M SUPER $\dagger$, AND M BARAITSER* \\ From *the Institute of Child Health, London; †Royal Manchester Children’s Hospital; $\ddagger W e s s e x$ Regional \\ Cytogenetics Unit, Salisbury; and §Queen Elizabeth Hospital for Children, London.
}

SUMMARY The inheritance of Angelman's syndrome, a disorder characterised by mental retardation, epilepsy, ataxia, and a happy disposition, is debated because affected sibs occur less frequently than expected with autosomal recessive inheritance. After discovering two unrelated patients with a small deletion of the proximal long arm of chromosome 15, 10 further patients with Angelman's syndrome were reassessed. Five had apparently normal karyotypes, four had a deletion within 15q11-13, and one had a pericentric inversion, inv(15)(p11q13) involving the same chromosomal region. In the latter case, the healthy mother had the same pericentric inversion, indicating that the patient also had a submicroscopic mutation on his other chromosome 15. These data map the Angelman locus to 15q11-13 and suggest that de novo visible deletions (associated with a low recurrence risk) and autosomal recessively inherited cases combine to give an overall sib recurrence risk of less than $25 \%$.

Angelman's syndrome ${ }^{1}$ (sometimes known as the 'happy puppet' syndrome) is characterised by mental retardation, profound speech delay, jerky voluntary movement, a happy disposition with paroxysms of laughter, tongue thrusting, and a characteristic facial appearance. The gradual evolution and subtlety of the facial dysmorphism, which includes a prominent jaw, wide mouth, and midfacial hypoplasia, has complicated the clinical diagnosis of patients in the past. Seizures are very common and the syndrome is associated with an unusual electroencephalogram (EEG) which is now recognised as a key diagnostic feature. ${ }^{2}$

The description of just two questionable affected sib pairs and one definite sib pair ${ }^{3}$ in reports up to 1982 led Williams and Frias ${ }^{4}$ to conclude in their review that there was little evidence of Mendelian inheritance in the group as a whole. Since that time, Fisher $e t a l^{5}$ reported a sib pair and, in reviewing the families of 38 previously reported cases, concluded that a $5 \%$ sib recurrence risk would be appropriate for genetic counselling. Baraitser et $a^{6}{ }^{6}$ described seven cases from three families and in the title of their report asked whether Angelman's syndrome might be an autosomal recessive condition after all.

Received for publication 19 July 1988.

Accepted for publication 8 August 1988.
Willems et $a l,{ }^{7}$ in reporting an affected sib pair, concluded that the sib recurrence risk was overall 1 to $2 \%$.

We report the association of Angelman's syndrome and chromosomal deletions within $15 q 11-13$, which not only provisionally maps the gene locus to this region, but is the first step towards elucidating the mechanism of inheritance in this condition.

\section{Subjects and methods}

In recalling families known to the Department of Paediatric Genetics, Institute of Child Health in February 1987 to explain our changing view on recurrence risks, the karyotype of patient 1 was reinvestigated because a 1985 chromosome analysis had shown what was interpreted as a variant chromosome 15 of no clinical significance. Detailed reanalysis in Salisbury showed a de novo deletion within 15q11-13. Independently, in Manchester, patient 2, who has the typical features of Angelman's syndrome, was found to have a de novo deletion within the same 15q11-13 region. Patients 3 to 12 were selected from a group of 36 children under review at The Hospitals for Sick Children/ Institute of Child Health who have a secure diagnosis of Angelman's syndrome with 
confirmatory EEG abnormalities ${ }^{8}$ because a previous routine chromosome preparation was available for reassessment. This group of 10 patients represents an unbiased consecutive series of Angelman's syndrome patients in whom chromosomes had been examined, but with no particular attention being paid to chromosome 15 . In nine, the initial report was 'normal karyotype', while in patient 3 , whose clinical diagnosis coincided with the start of this study, the deletion within 15q11-13 was noted on the initial report. The slides of all 12 chromosome preparations were analysed by one of us (JvdB) who was not involved in the initial reports. This allowed a direct comparison of the breakpoints and represented an additional opinion on all the karyotypes.

Chromosomes were prepared using PHA stimulated lymphocyte cultures in Iscove's low folate medium. Ethidium bromide $(10 \mu \mathrm{g} / \mathrm{ml})$ was added to the cultures two hours before harvest to produce more extended chromosomes for higher resolution banding analysis. $G$ banding was carried out using a trypsin-Giemsa method.

\section{Results}

The cytogenetic results are summarised in the table. Six patients have a deleted chromosome 15 . In case 6 the quality of the preparation did not allow the exact breakpoints to be determined.

In each of cases 1 to 5 the karyotypic description is $\operatorname{del}(15)(q 11 q 13)$. This deletion results in a shortening of the long arm, a deletion of band 15q12, and the amalgamation of pale bands $15 \mathrm{q} 11$ and $15 \mathrm{q} 13$. The pale area proximal to band $15 \mathrm{q} 14$ is variable in size between all the deleted patients and may
TABLE Chromosomal analysis in 12 children with Angelman's syndrome. Patients 1 and 2 were selected for inclusion because of chromosome 15 deletion. Patients 3 to으 12 are a representative sample.

\begin{tabular}{|c|c|c|}
\hline Patient & Karyotypic description & $\begin{array}{l}\text { Inheritance } \overrightarrow{\mathbb{D}} \\
\text { of chromosomad } \\
\text { abnormality }\end{array}$ \\
\hline $\begin{array}{l}1 \\
2 \\
3 \\
4 \\
5 \\
6 \\
7 \\
8 \text { (?affected sib) } \\
9 \text { (affected sib) } \\
10 \\
11 \\
12\end{array}$ & $\begin{array}{l}\text { 46,XY,del(15)(q11-13) } \\
\text { 46,XX,del(15)(q11-13) } \\
\text { 46,XY,del(15)(q11-13) } \\
\text { 46,XY,del(15)(q11-13) } \\
\text { 46,XY,del(15)(q11-13) } \\
\text { 46,XY,15q- } \\
\text { 46,XY,46 inv(15)(q11q13) } \\
\text { 46,XX } \\
\text { 46,XY } \\
\text { 46,XY } \\
\text { 46,XX } \\
46, X X\end{array}$ & $\begin{array}{l}\text { De novo } \\
\text { De novo } \\
\text { De novo } \\
\text { ? } \\
\text { De novo } \\
\text { From mother } \\
\end{array}$ \\
\hline
\end{tabular}

represent deletion of $15 q 11$ or $15 q 13$ or part of both $\Phi^{\text {Tे }}$ In patient 1 the pale area proximal to $q 14$ is of the normal size of $\mathrm{q} 13$ and thus there is the possibility that only part of $\mathrm{q} 12$ is deleted and that the remainder has merged with the centromeric bando that is, $\operatorname{del}(15)(\mathrm{q} 11.2 \mathrm{q} 12.1)$. Preliminary results from a flow karyotype analysis on patient 1 and his parents Ykindly performed by $\mathrm{A}$ Cooke at the Duncan Guthrie Institute of Medical Genetics $\frac{-}{0}$ Glasgow) indicated that patient 1 had a de nov deletion of his maternally derived chromosome $15 \frac{\mathrm{O}}{\mathrm{O}}$ Representative partial karyotypes of patients 1 and 2 are given in fig 1.

Where the parents' chromosomes had been examined (patients $1,2,3$, and 5) they did not show the same deletion.

Patient 7 did not appear to have a deletion but pericentric inversion involving breakpoints at the

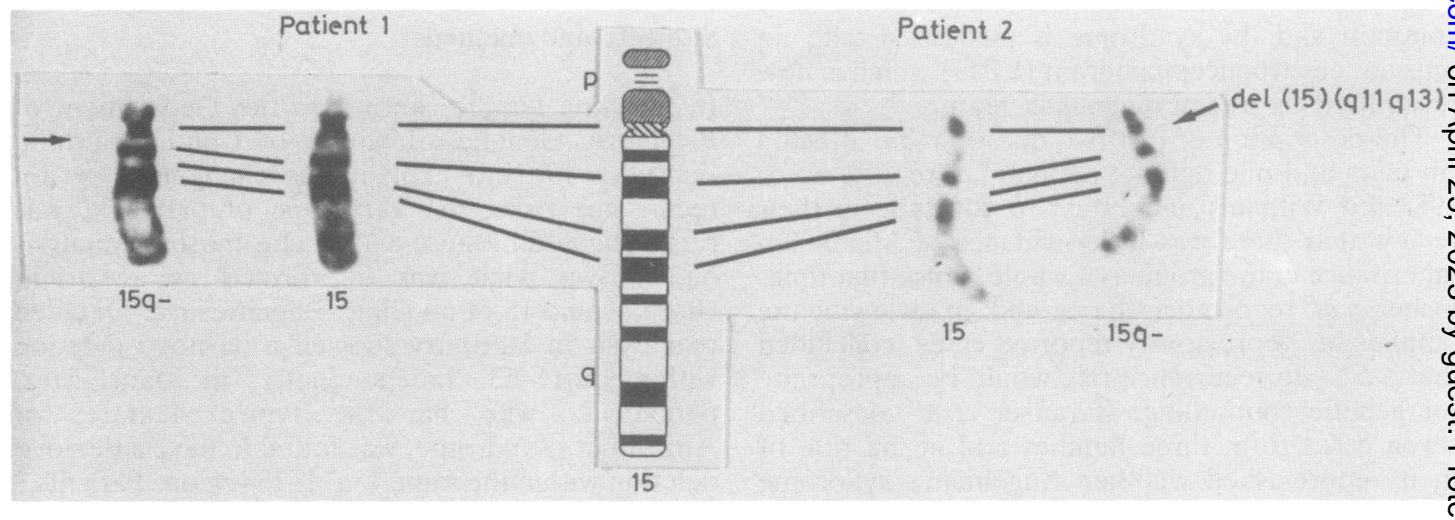

FIG 1 An idiogram of chromosome 15 showing dark and pale bands and lines to indicate the corresponding bands seen in $\stackrel{\odot}{\overparen{D}}$ the normal and deleted chromosomes 15 of patients 1 and 2. The top line indicates the centromere and the next line down the dark band q14. Pale band q11.2 and dark band $q 12$ are in between in the normal homologues. 
short arm region $15 \mathrm{p} 11$ and the long arm region $15 q 13$ (fig 2). This inversion was also present in this boy's mother; the father's chromosomes were normal. Patients 8 to 12 had no discernable abnormality.

Thus, in the representative sample of Angelman's syndrome (patients 3 to 12 ), $40 \%$ were deleted within 15q11-13, and an additional case had a pericentric inversion involving the same region of chromosome 15 .

\section{Discussion}

Reduction in the size of the small pale band nearest to the centromere, $15 q 11.2$, is common and the clinical significance difficult to assess. However, the six deletions described here extend to include the dark band 15q12. How frequently this latter type of deletion is seen in the general population is not known, but when in 1985 two of us (MF and MG) looked at a series of 93 patients referred consecutively for cytogenetic studies, band 15q11.2 appeared deleted in 19 cases, including patient 1 in the present study and his mother. These deletions were classified as total (that is, q12 was also missing or possibly amalgamated with the centromeric band) in one (patient 1), extensive in three (including the mother of patient 1 ), medium in four, and small in 11 patients.

These data, obtained well before this present study or the diagnosis of Angelman's syndrome in patient 1 , point to considerable normal variation in this region of chromosome 15 , although it is significant that patient 1 was the only one also to show apparent deletion of band 15q12. Thus, it seems that an interstitial deletion of this size extending from $15 q 11.2$ to $15 q 12$ is likely to be

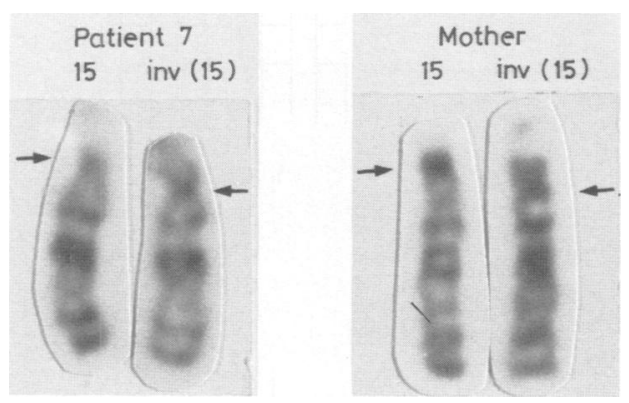

FIG 2 The chromosome 15 pair in patient 7 and his mother. Each have a normal chromosome 15 and have in common one with a pericentric inversion (inv(15)). The arrows indicate the position of the centromere which appears lower as a result of inversion of material between bands p11 and $q 13$. sufficiently rare in the general population to make the presence of it in $40 \%$ of Angelman's syndrome patients highly significant. This indicates that the Angelman's syndrome gene locus maps to this region of chromosome 15 .

During preparation of this manuscript there were two reports that supported our conclusion. Kaplan et $a l^{9}$ reported three children with different conditions associated with $15 q$ deletion, one of whom had Angelman's syndrome. Magenis et al ${ }^{10}$ described two girls with features of Angelman's syndrome who have a $15 q$ deletion. In both reports the $15 q 12$ region was involved.

Deletions within 15q11-13 are also associated with the Prader-Willi syndrome, ${ }^{11-13}$ with at least half the patients having a cytogenetically detectable deletion or chromosomal rearrangement at 15q11.2. ${ }^{8-10}$ Controversy has characterised research on the Prader-Willi deletion. Some investigators believe that patients who fit the strictest clinical criteria of the Prader-Willi syndrome all have chromosome 15 deletions or rearrangements. ${ }^{14} 15$ Others accept as clearly distinct from normal variation only deletions in which band $15 \mathrm{q} 12$ is also absent and find that $70 \%$ of Prader-Willi patients have such a deletion. ${ }^{16}$ The cytogenetic investigation of the Prader-Willi syndrome has demanded both rigorous clinical diagnosis and careful chromosome analysis and so it will be with Angelman's syndrome. It comes as no surprise that most of the initial routine cytogenetic reports regarded the karyotype as within normal limits.

Prader-Willi and Angelman's syndromes are clinically quite distinct. About $10 \%$ of Prader-Willi patients have seizures. Interestingly, there is an excess of blond/red hair and blue eyes (24/36) in Angelman's syndrome ${ }^{8}$ and oculocutaneous albinoidism is also a recognised feature of the Prader-Willi syndrome. ${ }^{17}$ Although both syndromes are associated with deletions within 15q11-13, the expectation is that deletions of different gene sequences are involved. The common deleted sequence in Prader-Willi syndrome appears to be 15q11.2. Patient 7 with Angelman's syndrome in the present study had a pericentric inversion disrupting band $15 q 13$ and if this rearrangement is causally related to his syndrome (see below) then perhaps the Angelman gene locus is within band q13.

Prader-Willi and Angelman's syndromes have different patterns of inheritance. The sib recurrence risk in Prader-Willi syndrome is only $1.6 \%{ }^{18}$ and there is still no convincing theory that explains all the cytogenetic findings, because partial trisomy and tetrasomy of 15q11-12, as well as deletions of this region, are associated with the syndrome. The sib recurrence risk in Angelman's syndrome is clearly 
much higher than in Prader-Willi syndrome and this raises the possibility that the inheritance in Angelman's syndrome might be a combination of simple autosomal recessive inheritance and 15q1113 chromosomal deletions, thereby producing an overall sib recurrence risk of somewhat less than $25 \%$. Two observations from the present pilot study must be borne in mind when considering the type of inheritance.

First, if one accepts that the pericentric inversion involving $15 q 13$ in patient 7 is causally related to Angelman's syndrome, then any hypothesis has to explain the fact that his mother appears to have exactly the same inversion but does not have the disease. Secondly, patient 9 , who has a sib with definite Angelman's syndrome, and patient 8 , who has a possibly affected sib, do not have visible deletions or chromosomal rearrangements. The most likely explanation for patient 9 is that he is homozygous for a recessively inherited mutation and his parents are asymptomatic carriers who face a 1 in 4 recurrence risk. On this line of reasoning it is possible that the pericentric inversion in patient 7 and his mother acts as a comparable recessively inherited mutation (perhaps resulting in down regulation of transcription of the relevant gene), but patient 7 also inherited a recessively inherited mutation from his father who just happened to be a carrier.

When it comes to large, cytogenetically detectable, de novo deletions of 15q11-13 there are two possible mechanisms. Either they combine with a mutation on the normal looking chromosome 15 , that is, these patients represent unmaskect heterozygotes, or the total deletion of the Angelman gene locus (loci) on a single chromsome 15 is sufficient to produce the disease. Both these situations would produce a low recurrence risk. The unmasked heterozygote hypothesis predicts a remarkably high frequency of $15 q$ deletions in healthy people, and the latter explanation, or some variation of it, seems more likely. One suchvariation is that we are dealing with a duplicatedw gene locus in normal people, akin to the two of globin genes on each chromosome 16, and, just like $\alpha$ thalassaemia, significant mutations may involvi just one or both chromosomes of the pair. ${ }^{19}$ i

Angelman's syndrome may arise when two of the four genes are defective. A large visible deletion could eliminate both genes on the same chromosome 15 and represent a dominant new mutation with $a_{T}$ low recurrence risk. Alternatively, a submicroscopie mutation affecting just one of the two genes on? chromosome 15 could have been inherited from both parents giving the same phenotypic effect but an autosomal recessive pattern of inheritance. Fig 300 summarises our current hypothesis on the inheritance, but more research is required before firm genetic advice can be given.

Whatever is eventually shown to be the true explanation, it seems that there is a high rate of chromosomal mutation within 15q11-13. There is considerable 'normal' variation observed in 15q11.2 $\overrightarrow{\vec{F}}$ a significant excess of translocation breakpoints within this region, ${ }^{20}$ and cloning instability of DNA segments from the $15 q 11-13$ region. ${ }^{21}$
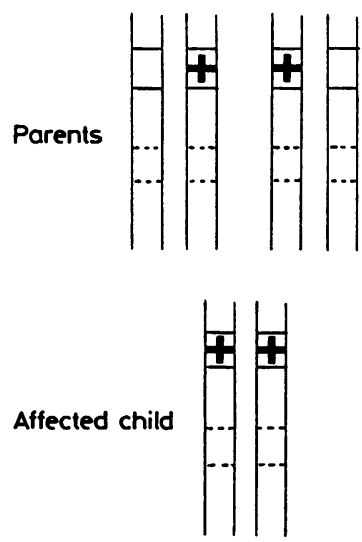

Autosomal recessive inheritance of submicroscopic mutation
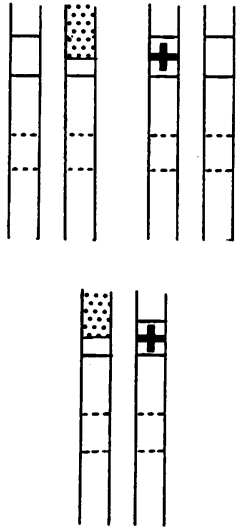

Pericentric inversion as a recessive mulation
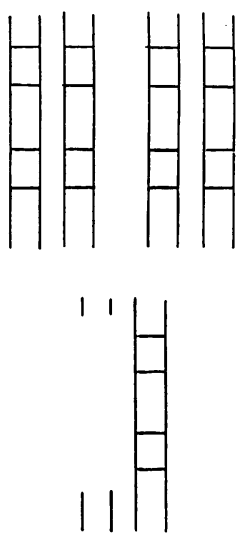

De novo deletion of both loci

Low recurrence risk

$25 \%$ recurrence risk

g that normally two gene loci are FIG 3 Diagram of three proposed mechanisms for causing Angelman's syndrome assuming that normally two gene loci are
active. The regions of chromosome 15 containing the Angelman loci are indicated for both parents and the affected child. 
In terms of possible mechanisms, Donlon et al ${ }^{21}$ pointed out that the inverted repeat DNA sequences they observed could be a cause for the chromosomal instability. It is also worth noting that during meiosis the chromosome 15 pair, like other D group chromosomes, tends to form chiasmata in the proximal region of the long arm as well as at the telomere, ${ }^{22} 23$ providing opportunities for 'unequal crossing over' and the generation of deletions.

These preliminary observations should allow further exploration of the role of $15 q$ deletions in the aetiology of Angelman's syndrome and eventually reliable prediction of the particular recurrence risk faced by the parents of any child with the syndrome. The use of DNA probes from this region ${ }^{21}$ should facilitate these investigations, allow the development of reliable prenatal diagnosis for this severely handicapping disorder, and eventually define the mutations that cause both Angelman's and Prader-Willi syndromes.

We would like to thank Drs Wilson, Brett, and Robb for their help and interest and Dr Richard Newton who originally diagnosed patient 2 .

\section{References}

1 Angelman H. Puppet children. A report of three cases. Dev Med Child Neurol 1965;7:681-8.

2 Boyd SG, Harden A, Patton MA. The EEG in early diagnosis of Angelman's (happy puppet) syndrome. Eur J Pediatr 1988; 147:508-13.

${ }^{3}$ Kuroki Y, Matsui I, Yamamoto Y, Ieshima A. Happy puppet syndrome in two siblings. Hum Genet 1980;56:227-9.

4 Williams CA, Frias JL. The Angelman 'happy puppet' syndrome. Am $J$ Med Genet 1982;11:453-60.

5 Fisher JA, Burn J, Alexander FW, Gardner-Medwin D. Angelman (happy puppet) syndrome in a girl and her brother. J Med Genet 1987;24:294-8.

${ }^{6}$ Baraitser M, Patton M, Lam STS, Brett EM, Wilson J. The Angelman (happy puppet) syndrome: is it autosomal recessive? Clin Genet 1987;31:323-30.

7 Willems PJ, Dijkstra I, Brouwer OF, Smit GPA. Recurrence risk in the Angelman ('happy puppet') syndrome. Am J Med Genet 1987;27:773-80.

${ }^{8}$ Robb SA, Pohl K, Baraitser M, Wilson J, Brett EM. The 'happy puppet' syndrome of Angelman - clinical features and genetic implications. Arch Dis Child (in press).
${ }^{9}$ Kaplan LC, Wharton R, Elias E, Mandell F, Donlon T, Latt SA. Clinical heterogeneity associated with deletions in the long arm of chromosome 15: report of 3 new cases and their possible genetic significance. Am J Med Genet 1987;28:45-53.

10 Magenis RE, Brown MG, Lacy DA, Budden S, LaFranchi S. Is Angelman syndrome an alternate result of $\operatorname{del}(15)(q 11 q 13)$ ? Am J Med Genet 1987;28:829-38.

11 Ledbetter DH, Riccardi VM, Airhart SD, Strobel RJ, Keenan BS, Crawford JD. Deletions of chromosome 15 as a cause of the Prader-Willi syndrome. N Engl J Med 1981;304:325-8.

12 Ledbetter DH, Mascarello JT, Riccardi VM, Harper VD, Airhart SD, Strobel RJ. Chromosomal 15 abnormalities and the Prader-Willi syndrome: a follow-up report of 40 cases. Am J Hum Genet 1982;34:278-85.

13 Fear CN, Mutton DE, Berry AC, Heckmatt JZ, Dubowitz VC. Chromosome 15 in Prader-Willi syndrome. Dev Med Child Neurol 1985;27:305-11.

14 Mattei JF, Mattei MG, Giraud F. Prader-Willi syndrome and chromosome 15. Hum Genet 1983;64:356-62.

${ }^{15}$ Niikawa N, Ishikiriyama S. Clinical and cytogenetic studies of the Prader-Willi syndrome: evidence of phenotype-karyotype correlation. Hum Genet 1985;69:22-7.

${ }^{16}$ Labidi F, Cassidy SB. A blind prometaphase study of PraderWilli syndrome: frequency and consistency in interpretation of del 15q. Am J Hum Genet 1986;39:452-60.

17 Hittner HM, King RA, Riccardi VM. Oculocutaneous albinoidism as a manifestation of reduced neural-crest derivatives in the Prader-Willi syndrome. Am J Ophthalmol 1982;94:328-37.

18 Clarren SK, Smith DW. Prader-Willi syndrome. Variable severity and recurrence risk. Am J Dis Child 1977;131:798-800.

19 Weatherall DJ, Clegg JB. The thalassaemia syndromes. 3rd ed. Oxford: Blackwell Scientific Publications, 1981.

20 Mattei MG, Soniah N, Mattei JF. Chromosome 15 anomalies and the Prader-Willi syndrome: cytogenetic analysis. Hum Genet 1984;66:313-34.

${ }^{21}$ Donlon TA, Lalande M, Wyman A, Bruns G, Latt SA. Isolation of molecular probes associated with the chromosome 15 instability in the Prader-Willi syndrome. Proc Natl Acad Sci USA 1986;83:4408-12.

22 Saadallah N, Hultén M. Chiasma distribution, genetic lengths, and recombination fractions: a comparison between chromosomes 15 and 16. J Med Genet 1983;20:290-9.

${ }^{23}$ Laurie DA, Hultén M. Further studies on chiasma distribution and interference in the human male. Ann Hum Genet 1985;49: 203-14.

Correspondence to Professor M E Pembrey, Mothercare Department of Paediatric Genetics, Institute of Child Health, 30 Guilford Street, London WC1N 1EH. 